\title{
Genetic factors and manganese-induced neurotoxicity
}

\author{
Pan Chen, Nancy Parmalee and Michael Aschner* \\ Department of Molecular Pharmacology, Albert Einstein College of Medicine, Bronx, NY, USA
}

\author{
Edited by: \\ Nora L. Nock, Case Western Reserve \\ University, USA \\ Reviewed by: \\ Marsha Ann Wilcox, Janssen \\ Pharmaceutical Research and \\ Development, USA \\ Martin Kolisek, Freie Universität \\ Berlin, Germany \\ Krishnan Sriram, Centers for Disease \\ Control - National Institute for \\ Occupational Safety and Health, USA

\section{${ }^{*}$ Correspondence:} \\ Michael Aschner, Department of \\ Molecular Pharmacology, Albert \\ Einstein College of Medicine, 1300 \\ Morris Park Avenue, Bronx, NY 10461 \\ USA \\ e-mail: michael.aschner@ \\ einstein.yu.edu
}

Manganese $(\mathrm{Mn})$, is a trace metal required for normal physiological processes in humans. Mn levels are tightly regulated, as high levels of $\mathrm{Mn}$ result in accumulation in the brain and cause a neurological disease known as manganism. Manganism shares many similarities with Parkinson's disease (PD), both at the physiological level and the cellular level. Exposure to high Mn-containing environments increases the risk of developing manganism. $\mathrm{Mn}$ is absorbed primarily through the intestine and then released in the blood. Excessive $\mathrm{Mn}$ is secreted in the bile and excreted in feces. Mn enters and exits cells through a number of non-specific importers localized on the cell membrane. Mutations in one of the $\mathrm{Mn}$ exporters, SLC30A10 (solute carrier family 30, member 10), result in Mn induced toxicity with liver impairments and neurological dysfunction. Four PD genes have been identified in connection to regulation of $\mathrm{Mn}$ toxicity, shedding new light on potential links between manganism and PD.

\section{Keywords: manganese, manganism, Parkinson's disease, neurotoxicity}

\section{INTRODUCTION}

Manganese $(\mathrm{Mn})$ is present in biological organisms in trace amounts and is necessary for optimal functioning of multiple enzymes, such as hydrolases, lyases, glutamine synthetase, and superoxide dismutase (SOD; Friberg et al., 1979; Wedler and Denman, 1984). Mn is also an essential cofactor for arginase (Roholt and Greenberg, 1956), an enzyme required for elimination of ammonia, as well as SOD, the principle mitochondrial antioxidant enzyme (McCord, 1976). In addition to these essential functions, Mn modulates the immune system, cell adhesion, as well as protein and carbohydrate metabolism (Grinnell, 1984; Smialowicz et al., 1985). Mn is required for proper bone and brain development (Frost et al., 1959; Sandstead, 1986), and $\mathrm{Mn}$ deficiency, while rare due to abundant $\mathrm{Mn}$ in the diet, can result in birth defects and seizures (Aschner, 2000, 2002). Mn levels are tightly regulated; however, excessive exposure to this metal may result in elevated brain accumulation and subsequent neurodegeneration, referred to as manganism.

Toxic exposures to $\mathrm{Mn}$ are most commonly seen in miners (Rodier, 1955), welders (Racette etal., 2001), and individuals working in and living around ferroalloy plants (Lucchini et al., 2007). As observed by T1-weighted magnetic resonance imaging (MRI), excessive levels of Mn accumulate preferentially in the basal ganglia (Inoue et al., 1991; Kulisevsky et al., 1992; Pujol etal., 1993; Butterworth etal., 1995; Weissenborn etal., 1995; Lucchini et al., 2000). The symptoms of idiopathic Parkinson's disease (PD) overlap considerably, but not completely, with manganism. In PD, the earliest symptoms include loss of smell and sleep disorders, followed by difficulty with balance, gait disturbance, and unilateral resting tremor (Parkinson, 2002). Presentation varies considerably among patients. The disease typically progresses to include bradykinesia, rigidity, postural instability, masked facial expression, and difficulty with speech and swallowing. PD patients may develop visual symptoms, including a decline in visual perception, disturbances of visuospatial orientation, facial recognition problems, and chronic visual hallucinations (Armstrong, 2011). A substantial portion of PD patients also experience depression and/or dementia. Neuropathologically, $\mathrm{PD}$ is characterized by the loss of dopaminergic (DAergic) neurons in the substantia nigra (SN) pars compacta, and the presence of Lewy bodies, neuronal protein aggregates that are composed of alpha-synuclein and other proteins (Jellinger, 2012).

\section{NEUROTOXICITY INDUCED BY Mn EXPOSURE HISTORY AND SYMPTOMS OF MANGANISM}

Mn toxicity was first described by Couper (1837) reporting his observations of five manganese ore crushers with muscular weakness, paraplegia, tremor, whispering speech, and a tendency to lean forward while walking. In two of the workers, symptoms progressed even after removal from the Mnore crushing operations. The remaining three workers were removed from $\mathrm{Mn}$ exposure at the first signs of muscle weakness in the lower extremities. In these three workers, the symptoms abated following removal from Mn exposure. Manganism was also described by Rodier (1955) in a group of Moroccan miners, by Mena et al. (1967) in a group of Chilean miners, and by Huang et al. (1989) in six Taiwanese ferromanganese plant workers. Of $\sim 4000$ miners working in three mines in Morocco, Rodier saw 150 cases of manganism, all in workers who spent considerable time underground, presumably with limited ventilation and a high degree of inhalation exposure. In these workers, onset of symptoms occurred after months to years of work. In contrast, Racette (2013) noted that contemporary exposures are much lower, and onset of symptoms tends 
to occur after years or decades of exposure. Mena described Mn turnover in patients compared to healthy miners using injected ${ }^{54} \mathrm{Mn}$ radioisotope and found significantly faster turnover rates in the healthy miners as compared to miners diagnosed with manganism. Huang described six patients who worked in a factory with inadequate ventilation. Follow up studies on these patients indicate that after removal from $\mathrm{Mn}$ exposure, their symptoms continued to worsen for approximately ten years, after which their condition remained constant with severe extrapyramidal dysfunction (Huang et al., 1993, 1998, 2007). Early features of manganism include weakness, anorexia, behavioral, and psychiatric disturbances, difficulty sleeping, impotence, and attention disorders. This early stage is characterized by emotional lability that has been termed "manganese madness." Patients have described an awareness that their behavior is unusual or abnormal, but an inability to control their outward affect. There is some evidence that if Mn exposure is discontinued at an early stage, these symptoms may revert. However, with acute exposure, progression often occurs even after Mn exposure has ceased. MRI shows clearing of Mn from the globus pallidus (GP) in three to six months (Roth, 2009). In some patients with severe exposure, neurodegenerative signs progress even after removal from exposure. Later symptoms include extrapyramidal deficits including bradykinesia, rigidity, difficulty with gait, specifically a dystonic movement of the foot known as "cock walk," and a tendency to fall backward. Masked facial expressions and micrographia are also present in manganism, as in PD (Couper, 1837; Rodier, 1955; Mena et al., 1967). Tremor in manganism tends to be slight or absent as compared to PD. Manganism patients do not typically respond therapeutically to L-DOPA (Shinotoh et al., 1997; Koller et al., 2004).

\section{MANGANISM AND PARKINSON'S DISEASE: SIMILARITY AND DIFFERENCES}

There is evidence that genes involved in susceptibility to PD are also involved in Mn uptake and homeostasis (discussed in more detail below), leading to the hypothesis that there are common mechanisms of neurodegeneration to manganism and PD. In each cohort, only a subset of exposed individuals developed signs of manganism. It is unknown why some individuals are apparently able to maintain Mn homeostasis in the presence of high exposures, while others accumulate toxic levels of the metal leading to neurodegeneration, or why some individuals improve following cessation of exposure, while others progress. The distinction between manganism and PD is typically made based on exposure history, however, in areas with high levels of naturally or industrially occurring $\mathrm{Mn}, \mathrm{PD}$ prevalence is higher than in surrounding regions or national registries (Lucchini et al., 2007), indicating that the distinction between PD and manganism may not be entirely clear, especially for chronic, long-term exposures. Understanding the molecular genetics of Mn transport and toxicity may lead to a new understanding of the mechanisms underlying PD.

\section{FACTORS REGULATING Mn TRANSPORT AND TOXICITY ENVIRONMENTAL FACTORS}

As the 5th most abundant metal and the 12th most abundant element on the earth, Mn is present in air, soil, and water. Mn is taken up primarily through the intestine and then circulated in the blood (Davis et al., 1993; Finley et al., 1994). Excessive Mn is secreted via the bile, returning to the intestine and excreted in feces (Davis et al., 1993; Malecki et al., 1996). Mn may also enter the human body by inhalation of fumes containing the metal (Jorge da Silva et al., 2008). It is also secreted through urine and sweat, but in smaller amounts (vs. bile; Cohn and Emmett, 1978; Davis et al., 1993).

Given the abundance of $\mathrm{Mn}$ in the environment, humans are exposed to different levels of Mn. Rice, nuts, whole grains, and legumes, as well as green vegetables, tea, and certain fruits contain high Mn levels (ATSDR, 2012). Food-borne Mn levels generally supply the basic dietary requirement for humans without causing disease. However, excessive exposure to environmental Mn results in toxicity. Workers in mining, welding, and smelting industries may be potentially exposed to high Mn levels (Criswell et al., 2012; Racette et al., 2012), as well as individuals residing in the vicinity of Mn associated industries. Exposures to high Mn levels have been associated with greater risk for PD (Racette et al., 2012; Smith et al., 2012). Additional exposures to Mn have been documented from gasoline, steel, fireworks, batteries, leather, glass, ceramics, cosmetics, and textiles, as well as certain pesticides and fungicides (such as Maneb and Mancozeb; ATSDR, 2012). In addition to exposure in high Mn containing environments, patients with dysfunctional biliary system (e.g., those requiring parenteral nutrition) are also more susceptible to $\mathrm{Mn}$ induced toxicity, as optimal liver function is required for Mn secretion. In addition, infants and children that receive $\mathrm{Mn}$-containing supplements may be at risk to $\mathrm{Mn}$ toxicity, as younger individuals tend to absorb and maintain higher Mn levels compared to adults reflecting a greater requirement for Mn in cellular activities (Keen et al., 1986; Zlotkin et al., 1995). Iron (Fe)-deficient individuals are also at a greater risk for $\mathrm{Mn}$ poisoning, as the two metals compete for shared transporters (see below). In recent years, Methcathinone abuse has been linked to manganism, due to the presence of $\mathrm{Mn}$ as an impurity (derived from potassium permanganate; Sikk et al., 2013).

\section{GENETIC FACTORS}

\section{Transporters importing extracellular Mn (Table 1)}

Mn enters cells by various transporters (importers) located at the plasma membrane. These transporters are tightly regulated, maintaining optimal Mn levels in cells. The divalent metal transporter 1 (DMT1) is the primary divalent $\mathrm{Mn}\left(\mathrm{Mn}^{2+}\right)$ transporter. It is localized at the plasma membrane (Burdo et al., 2001a) and functions to import $\mathrm{Mn}^{2+}$ from the extracellular matrix into cells (Bell et al., 1989; Aschner and Gannon, 1994; Erikson and Aschner, 2002; Garrick et al., 2003; Au et al., 2009). DMT1 is highly expressed in basal ganglia, such as SN, GP, hypothalamic nucleus, and striatum (Williams et al., 2000; Burdo et al., 2001b; Huang et al., 2004), areas that are known to accumulate high Mn levels (Suzuki et al., 1975; Newland et al., 1989; Rose et al., 1999; Ikeda et al., 2000; Jorge da Silva et al., 2008). In addition to DMT1, other transmembrane proteins also import $\mathrm{Mn}^{2+}$, including the citrate transporter (Crossgrove et al., 2003), zinc transporters ZIP8 (He et al., 2006; Himeno et al., 2009; Fujishiro et al., 2011), calcium channels (Mason, 1993; Lucaciu et al., 1997; Finley, 1998), the choline transporter (Lockman et al., 2001), dopamine transporter 
Table 1 | Different types of Mn transporters in a cell.

\begin{tabular}{|c|c|c|c|}
\hline $\begin{array}{l}\text { Types of Mn } \\
\text { transporters }\end{array}$ & Name & Localization & Roles in Mn transportation \\
\hline Exporters & Fpn, SLC30A10 & Plasma membrane & Export cytosolic $\mathrm{Mn}$ to extracellular matrix \\
\hline & $\mathrm{Na}^{+}$-independent mechanisms & Mitochondrial membrane & Export mitochondrial Mn to cytosol \\
\hline & SPCA1 & Golgi membrane & Import cytosolic Mninto the Golgi lumen \\
\hline
\end{tabular}

(DAT; Ingersoll et al., 1999), and a cation-transporting ATPase 13A2 (ATP13A2 or Park9; Gitler et al., 2009; Tan et al., 2011). Trivalent $\mathrm{Mn}\left(\mathrm{Mn}^{3+}\right)$ enters cells primarily via the transferrin receptor (TfR) mechanism (Morris et al., 1992). Notably, none of these proteins is a specific Mn transporter, and they transport additional metals, such as iron, calcium, zinc, etc. Currently, few human diseases are known to be associated with mutations in these importers, with the exception of Park9 and DMT1. Park9 represents a well-known risk factor for PD. High levels of Fe were found in brain due to altered DMT1 expression (Urrutia et al., 2013). Mutations in DMT1 that impair Fe transport protect rodents against parkinsonism-inducing neurotoxins, such as MPTP and 6-hydroxydopamine (Salazar et al., 2008), consistent with a role for DMT1 in Fe-mediated neurodegeneration in PD. He et al. (2011) reported that the CC haplotype in the DMT1 gene is a possible risk factor for PD in the Han Chinese population. Whether mutations in DMT1 alter Mn levels in the brains of these individuals has yet to be determined.

\section{Transporters exporting intracellular Mn (Table 1)}

Cells export excessive $\mathrm{Mn}$ from the cytoplasm to the extracellular matrix, as high Mn levels result in cellular toxicity. Recently, ferroportin (Fpn) was recognized as putative $\mathrm{Mn}$ exporter. It transports extracellularly both $\mathrm{Fe}^{2+}$ and $\mathrm{Mn}^{2+}$ (Yin et al., 2010; Madejczyk and Ballatori, 2012). To date, no human diseases have been ascribed to mutations or dysfunction of this protein, indicating that Fpn is unlikely to be the primary Mn exporter. Recently, a gene named SLC30A10 (solute carrier family 30 member 10) was identified in patients with hepatic cirrhosis, dystonia, polycythemia, and hypermanganesemia, concomitant with high Mn brain levels (Quadri et al., 2012; Stamelou et al., 2012; Tuschl etal., 2012). SLC30A10 is localized at the cell membrane, and mutations in this gene either result in early truncation of this protein or amino acid substitution (Quadri et al., 2012; Stamelou et al., 2012; Tuschl et al., 2012). Interestingly, none of the patients were exposed to excessive Mn, yet they displayed symptoms consistent with PD (Quadri et al., 2012; Stamelou etal., 2012; Tuschl et al., 2012). SLC30A10 is the only protein known to cause Mn toxicity when mutated, indicating it may be a primary and a key regulator of $\mathrm{Mn}$ export. Our recent data have shown that the wildtype (WT) SLC30A10protein when expressed in in Caenorhabditis elegans (C. elegans), protects against $\mathrm{Mn}^{2+}$ induced lethality and DAergic neurodegeneration, as well as locomotion deficits (basal slowing response, which is regulated by DAergic neurons; unpublished data). It remains unclear whether SCL30A10 is a specific Mn exporter or if it also transports additional metals. Notably, it was originally posited to be a specific zinc transporter (Seve et al., 2004; Bosomworth etal., 2012). Further research is needed to better understand its function and a compound screen could be profitably directed at identifying specific modulators of this transporter, potentially leading to novel therapies in patients with manganism.

\section{Intracellular Mn transporters (Table 1)}

Once inside the cell, $\mathrm{Mn}$ is transported into various organelles to fulfill its function, thus limiting its potential toxicity from accumulating at high levels in the cytosol. The mitochondria contain the highest Mn levels (Gavin etal., 1999). Mitochondrial SOD requires $\mathrm{Mn}$ as a cofactor for optimal function (Borgstahl et al., 1992). The calcium $\left(\mathrm{Ca}^{2+}\right)$ uniporter imports cytosolic $\mathrm{Mn}^{2+}$ into the mitochondria lumen (Drahota et al., 1969; Gunter and Puskin, 1972; Gunter et al., 1975), and excessive $\mathrm{Mn}^{2+}$ is exported out of mitochondria through sodium $\left(\mathrm{Na}^{+}\right)$-independent mechanisms (Gavin et al., 1990). The Golgi apparatus can store excessive $\mathrm{Mn}^{2+}$ and this is mediated by $\mathrm{Ca}^{2+} / \mathrm{Mn}^{2+}$ ATPase isoform 1 (SPCA1). SPCA1 is localized at the Golgi membrane and imports $\mathrm{Mn}^{2+}$ from the cytosol to the Golgi lumen (Murin et al., 2006). $\mathrm{Mn}$ in the Golgi is secreted extracellularly through a secretory pathway. Although the nucleus also contains high levels of $\mathrm{Mn}$, the transporters localized to the nuclear membrane remain unknown and future studies are needed to identify these Mn transporters.

\section{PD-associated proteins involved in Mn-induced toxicity (Table 2)}

As described above, manganism shares many similar symptoms with PD. ATP13A2 and DAT both are able to transport Mn. Notably mutations in ATP13A2 cause a parkinsonian-like syndrome, Kufor-Rakeb syndrome (KRS). KRS is an autosomal recessive disorder characterized by subacute, juvenile-onset, 
Table 2 | PD-associated proteins involved in Mn-induced toxicity.

\begin{tabular}{lll}
\hline $\begin{array}{l}\text { PD-associated } \\
\text { proteins }\end{array}$ & Cellular activity & Roles in Mn toxicity \\
\hline ATP13A2 & Inorganic cation transporter & Importing extracellular Mn into cytoplasm \\
DAT & DA transporter & Importing extracellular Mn into cytoplasm \\
Parkin & E3 ubiquitin ligase & Enhancing Mn accumulation when mutated \\
DJ-1 & Antioxidant peptidase & Enhancing Mn accumulation when mutated \\
$\alpha$-Synuclein & Presynaptic protein in synaptic vesicle trafficking & Reducing Mn accumulation in parkin and DJ-1 mutants \\
& and recycling & \\
UCH-L1 & Ubiquitin ligase & Unknown \\
NURR1 & Transcription factor & Unknown \\
PINK1 & Serine/threonine kinase & Unknown \\
LRRK2 & Protein kinase & Unknown \\
\hline
\end{tabular}

and is levodopa-responsive. It is unknown whether mutations in ATP13A2 change its affinity for different cations, specifically $\mathrm{Mn}$, resulting in increased $\mathrm{Mn}$ accumulation in the brain. DAT removes synaptic dopamine into the presynaptic membrane for recycling. In PD patients, DAT activity is significantly decreased (Sossi etal., 2007). In C. elegans, dat knockout mutants are resistant to DAergic neurodegeneration induced by $\mathrm{Mn}$ exposure, but show a lower survival rate (Benedetto et al., 2010). Mutations in $\alpha$-synuclein, parkin, and DJ-1, all of which are associated with early onset PD, have also been shown to alter Mn transport (Bornhorst et al., 2014). $\alpha$-synuclein encodes a presynaptic protein involved in synaptic vesicle trafficking and recycling (Gitler et al., 2008; Ben Gedalya et al., 2009). Point mutations (A30P and A53T) or duplication of $\alpha$-synuclein result in loss of DAergic neurons concomitant with oxidative stress, protein aggregation, and Lewy bodies formation (Narhi et al., 1999; Hsu et al., 2000; Masliah et al., 2000; Kuwahara et al., 2006), the hallmarks of PD. Parkin encodes an E3 ubiquitin ligase (Shimura et al., 2000) responsible for degradation of abnormal proteins. Mutations in parkin result in DAergic neurodegeneration with increased oxidative stress, yet in the absence of Lewy bodies (Yang et al., 2006). It is known that overexpression of parkin is able to decrease $\alpha$-synuclein protein aggregation (Petrucelli et al., 2002; Yang et al., 2003). DJ-1 encodes a protein of the peptidase C56 family. It functions as a peroxidase (Andres-Mateos et al., 2007), a chaperone (Shendelman et al., 2004), a metal binding protein (Björkblom et al., 2013), and a regulatory subunit of an RNA binding complex (Hod et al., 1999), thus protecting cells from oxidative stress (Mitsumoto and Nakagawa, 2001; Mitsumoto et al., 2001), $\alpha$-synuclein aggregation (Zhou et al., 2009), and metal induced cell death (Björkblom et al., 2013). It also regulates androgen receptor-dependent transcription (Takahashi et al., 2001). Mutations in DJ-1 result in increased oxidative stress and DAergic neurodegeneration. Recently, Chakraborty and colleagues found that $p d r-1$ (worm homolog of parkin) and djr-1.1 (worm homolog of $D J-1$ ) mutants show enhanced Mn accumulation and increased oxidative stress in $C$. elegans and these effects may be reduced by expression of WT human $\alpha$-synuclein (Bornhorst et al., 2014).
Interestingly, WT $\alpha$-synuclein also protected against DAergic neurodegeneration induced by $\mathrm{Mn}$ exposure in $p d r-1$ (the homolog of mammalian parkin/PARK2) mutant worms (Bornhorst et al., 2014).

In addition to the above proteins, there are other PDassociated proteins whose effect on $\mathrm{Mn}$-induced toxicity remains unknown. These PD genes include ubiquitin carboxy-terminal hydrolase L1 (UCH-L1), NUR-Related factor 1 (NURR1), PTENINduced Kinase 1 (PINK1) and Leucine-Rich Repeat Kinase 2 (LRRK2). UCH-L1 (or PARK5) is an enzyme expressed in neurons throughout the brain that hydrolyzes C-terminal ubiquitinyl esters to recycle ubiquitin after degradation of misfolded proteins (Wilkinson, 2000; Meray and Lansbury, 2007). Similar to parkin, it also functions as an ubiquitin ligase to prevent protein aggregation (Liu et al., 2002; Gong et al., 2006; Lansbury, 2006). NURR1 is a transcription factor predominantly expressed in central DAergic neurons (Bäckman et al., 1999; Jankovic et al., 2005). It is critical for development and maintenance of the DAergic system as it regulates the expression of tyrosine hydroxylase (TH; Sakurada et al., 1999), DAT (Sacchetti et al., 2001), vesicular monoamine transporter 2 (VMAT2), and aromatic L-amino acid decarboxylase (AADC; Hermanson etal., 2003). PINK1 (or PARK6) is a mitochondrial targeted serine/threonine kinase, with substrates in the cytosol (Zhou et al., 2008). Recent studies indicate that PINK1, together with parkin, is involved in a mitochondrial quality control system to regulate mitochondrial dynamics and function, and protects against cellular stress (Valente et al., 2004; Clark etal., 2006). LRRK2 or PARK8 is a protein kinase expressed preferentially in DAergic neurons (Han et al., 2008). It interacts with parkin in the cytosol and overexpression of either WT LRRK2 or gain-of-function mutants results in DAergic neurodegeneration (Smith et al., 2005). Together, these proteins either interact with parkin or have similar function to parkin. Given that parkin is involved in regulation of Mn toxicity, these PD-related proteins may play a role in Mn-induced toxicity. Future studies could be profitably directed at the studies on how mutations in these genes enhance basal ganglia Mn accumulation. 


\section{CONCLUSION}

$\mathrm{Mn}$ is required for multiple physiological processes. It is a cofactor for various enzymes and plays important roles in mediating oxidative stress responses, regulation of immune responses, carbohydrate metabolism, energy production, cell adhesion and protein modification (Benedetto et al., 2009). Although Mn deficiency results in birth defects and poor bone development, given its abundant and ubiquitous presence in the environment, $\mathrm{Mn}$ overexposure represents a more critical contemporary concern. Excessive accumulation of $\mathrm{Mn}$ in the brain may cause DAergic neurodegeneration and manganism, the latter sharing a clinical picture analogous to PD. At the cellular level, excessive Mn levels have been associated with increased oxidative stress, impaired ATP production, protein aggregation and mitochondrial dysfunction. $\alpha$-synuclein aggregation or Lewy bodies are absent in the brains of manganism patients. Given the similarities between manganism and $\mathrm{PD}, \mathrm{Mn}$ is considered an important environmental factor in causing sporadic $\mathrm{PD}$, especially given recent discoveries that certain PD genes (ATP13A2, parkin, DJ-1, and $\alpha$-synuclein) are involved in Mn transport and/or toxicity.

Genetic factors associated with Mn toxicity remain to be explored. Several Mn importers have been identified; however, none have mutations associated with Mn related diseases. Compared to the plethora of Mn importers, knowledge about Mn exporters is limited. Fpn and SCL30A10 are the only two exporters identified to date. Among all known Mn transporters, SLC30A10 appears to be a key regulator of $\mathrm{Mn}$ homeostasis, given that mutations in this genecan result in manganism in the absence of overexposure to this metal. SLC30A10 localizes at the cell membrane, exports $\mathrm{Mn}$ from cells and affords protection in various experimental models.

Several PD associated genes, namely, either transport $\mathrm{Mn}$ (ATP13A2; Gitler et al., 2009; Tan et al., 2011) or mediate Mninduced toxicity (parkin, DJ-1, and $\alpha$-synuclein; Bornhorst et al., 2014). These results tightly correlate PD with Mn toxicity, supporting the idea of $\mathrm{Mn}$ as an environmental factor of PD. It will be of particular interest to study brain Mn levels in PD patients carrying mutations in these genes. Given the similarity between manganism and PD, it is possible that other well known PD genes (UCH-L1, NURR1, PINK1, and LRRK2) also play a role in regulating Mn homeostasis. Future studies should be focused on the relationship between $\mathrm{PD}$-associated proteins and their potential to alter Mn transport and/or toxicity.

\section{ACKNOWLEDGMENT}

The manuscript was supported by NIH grant NIEHS R01 10563.

\section{REFERENCES}

Andres-Mateos, E., Perier, C., Zhang, L., Blanchard-Fillion, B., Greco, T. M., Thomas, B., et al. (2007). DJ-1 gene deletion reveals that DJ-1 is an atypical peroxiredoxin-like peroxidase. Proc. Natl. Acad. Sci. U.S.A. 104, 14807-14812. doi: 10.1073/pnas.0703219104

Armstrong, R. A. (2011). Visual symptoms in Parkinson's disease. Parkinsons Dis. 2011:908306. doi: 10.4061/2011/908306

Aschner, M. (2000). Manganese: brain transport and emerging research needs. Environ. Health Perspect. 108(Suppl. 3), 429-432. doi: 10.1289/ehp.00108s3429

Aschner, M. (2002). Open issues from the 15th International Conference on Manganese. Neurotoxicology 23, 123-125. doi: 10.1016/S0161-813X(01)00097-3
Aschner, M., and Gannon, M. (1994). Manganese (Mn) transport across the rat blood-brain barrier: saturable and transferrin-dependent transport mechanisms. Brain Res. Bull. 33, 345-349. doi: 10.1016/0361-9230(94)90204-6

ATSDR. (2012). Toxicological Profile for Manganese. Atlanta, GA: U.S. Department of Health and Human Services, Public Service.

Au, C., Benedetto, A., Anderson, J., Labrousse, A., Erikson, K., Ewbank, J. J., et al. (2009). SMF-1, SMF-2, and SMF-3 DMT1 orthologues regulate and are regulated differentially by manganese levels in C. elegans. PLOS ONE 4:e7792. doi: 10.1371/journal.pone.0007792

Bäckman, C., Perlmann, T., Wallén, Å., Hoffer, B. J., and Morales, M. (1999). A selective group of dopaminergic neurons express Nurr 1 in the adult mouse brain. Brain Res. 851, 125-132. doi: 10.1016/S0006-8993(99)02149-6

Bell, J. G., Keen, C. L., and Lonnerdal, B. (1989). Higher retention of manganese in suckling than in adult rats is not due to maturational differences in manganese uptake by rat small intestine. J. Toxicol. Environ. Health 26, 387-398. doi: 10.1080/15287398909531263

Benedetto, A., Au, C., and Aschner, M. (2009). Manganese-induced dopaminergic neurodegeneration: insights into mechanisms and genetics shared with Parkinson's disease. Chem. Rev. 109, 4862-4884. doi: 10.1021/cr800536y

Benedetto, A., Au, C., Avila, D. S., Milatovic, D., and Aschner, M. (2010). Extracellular dopamine potentiates $\mathrm{mn}$-induced oxidative stress, lifespan reduction, and dopaminergic neurodegeneration in a BLI-3-dependent manner in Caenorhabditis elegans. PLoS Genet. 6:e1001084. doi: 10.1371/journal.pgen.1001084

Ben Gedalya, T., Loeb, V., Israeli, E., Altschuler, Y., Selkoe, D. J., and Sharon, R. (2009). $\alpha$-synuclein and polyunsaturated fatty acids promote clathrinmediated endocytosis and synaptic vesicle recycling. Traffic 10, 218-234. doi: 10.1111/j.1600-0854.2008.00853.x

Björkblom, B., Adilbayeva, A., Maple-Grødem, J., Piston, D., Ökvist, M., Xu, X. M., et al. (2013). Parkinson disease protein DJ-1 binds metals and protects against metal-induced cytotoxicity. J. Biol. Chem. 288, 22809-22820. doi: 10.1074/jbc.M113.482091

Borgstahl, G. E., Parge, H. E., Hickey, M. J., Beyer, W. F. Jr., Hallewell, R. A., and Tainer, J. A. (1992). The structure of human mitochondrial manganese superoxide dismutase reveals a novel tetrameric interface of two 4-helix bundles. Cell 71, 107-118. doi: 10.1016/0092-8674(92)90270-M

Bornhorst, J., Chakraborty, S., Meyer, S., Lohren, H., Brinkhaus, S. G., Knight, A. L., et al. (2014). The effects of pdr1, djr1.1 and pink1 loss in manganese-induced toxicity and the role of $\alpha$-synuclein in C. elegans. Metallomics 6, 476-490. doi: 10.1039/C3MT00325F

Bosomworth, H. J., Thornton, J. K., Coneyworth, L. J., Ford, D., and Valentine, R. A. (2012). Efflux function, tissue-specific expression and intracellular trafficking of the $\mathrm{Zn}$ transporter $\mathrm{ZnT} 10$ indicate roles in adult $\mathrm{Zn}$ homeostasis. Metallomics 4, 771-779. doi: 10.1039/C2MT20088K

Burdo, J. R., Menzies, S. L., Simpson, I. A., Garrick, L. M., Garrick, M. D., Dolan, K. G., et al. (2001a). Distribution of divalent metal transporter 1 and metal transport protein 1 in the normal and Belgrade rat. J. Neurosci. Res. 66, 1198-1207. doi: 10.1002/jnr.1256

Burdo, J. R., Menzies, S. L., Simpson, I. A., Garrick, L. M., Garrick, M. D., Dolan, K. G., et al. (2001b). Distribution of divalent metal transporter 1 and metal transport protein 1 in the normal and Belgrade rat. J. Neurosci. Res. 66, 1198-1207. doi: 10.1002/jnr.1256

Butterworth, R. F., Spahr, L., Fontaine, S., and Layrargues, G. P. (1995). Manganese toxicity, dopaminergic dysfunction and hepatic encephalopathy. Metab. Brain Dis. 10, 259-267. doi: 10.1007/BF02109357

Clark, I. E., Dodson, M. W., Jiang, C., Cao, J. H., Huh, J. R., Seol, J. H., et al. (2006). Drosophila pink1 is required for mitochondrial function and interacts genetically with parkin. Nature 441, 1162-1166. doi: 10.1038/nature04779

Cohn, J. R., and Emmett, E. A. (1978). The excretion of trace metals in human sweat. Ann. Clin. Lab. Sci. 8, 270-275.

Couper, J. (1837). On the effects of black oxide manganese when inhaled into the lungs. Brit. Ann. Med. Pharm. Vital Stat. Gen. Sci. 1, 41-42.

Criswell, S. R., Perlmutter, J. S., Huang, J. L., Golchin, N., Flores, H. P., Hobson, A., et al. (2012). Basal ganglia intensity indices and diffusion weighted imaging in manganese-exposed welders. Occup. Environ. Med. 69, 437-443. doi: 10.1136/oemed-2011-100119

Crossgrove, J. S., Allen, D. D., Bukaveckas, B. L., Rhineheimer, S. S., and Yokel, R. A. (2003). Manganese distribution across the blood-brain barrier. I. Evidence for carrier-mediated influx of managanese citrate as well as manganese 
and manganese transferrin. Neurotoxicology 24, 3-13. doi: 10.1016/S0161813X(02)00089-X

Davis, C. D., Zech, L., and Greger, J. L. (1993). Manganese metabolism in rats: an improved methodology for assessing gut endogenous losses. Proc. Soc. Exp. Biol. Med. 202, 103-108. doi: 10.3181/00379727-202-43518

Drahota, Z., Gazzotti, P., Carafoli, E., and Rossi, C. S. (1969). A comparison of the effects of different divalent cations on a number of mitochondrial reactions linked to ion translocation. Arch. Biochem. Biophys. 130, 267-273. doi: 10.1016/00039861(69)90033-2

Erikson, K., and Aschner, M. (2002). Manganese causes differential regulation of glutamate transporter (GLAST) taurine transporter and metallothionein in cultured rat astrocytes. Neurotoxicology 23, 595-602. doi: 10.1016/S0161-813X(02) 00012-8

Finley, J. W. (1998). Manganese uptake and release by cultured human hepatocarcinoma (Hep-G2) cells. Biol. Trace Elem. Res. 64, 101-118. doi: 10.1007/ BF02783328

Finley, J. W., Johnson, P. E., and Johnson, L. K. (1994). Sex affects manganese absorption and retention by humans from a diet adequate in manganese. Am. J. Clin. Nutr. 60, 949-955.

Friberg, L., Nordberg, G., and Vouk, V. B. (1979). Handbook on the Toxicology of Metals. Amsterdam: Elsevier/North-Holland Biomedical Press.

Frost, G., Asling, C. W., and Nelson, M. M. (1959). Skeletal deformities in manganese-deficient rats. Anat. Rec. 134, 37-53. doi: 10.1002/ar.10913 40105

Fujishiro, H., Doi, M., Enomoto, S., and Himeno, S. (2011). High sensitivity of RBL-2H3 cells to cadmium and manganese: an implication of the role of ZIP8 Metallomics 3, 710-718. doi: 10.1039/c1mt00020a

Garrick, M. D., Dolan, K. G., Horbinski, C., Ghio, A. J., Higgins, D., Porubcin, M., et al. (2003). DMT1: a mammalian transporter for multiple metals. Biometals 16, 41-54. doi: 10.1023/A:1020702213099

Gavin, C. E., Gunter, K. K., and Gunter, T. E. (1990). Manganese and calcium efflux kinetics in brain mitochondria. Relevance to manganese toxicity. Biochem. J. 266, 329-334.

Gavin, C. E., Gunter, K. K., and Gunter, T. E. (1999). Manganese and calcium transport in mitochondria: implications for manganese toxicity. Neurotoxicology 20, 445-453.

Gitler, A. D., Bevis, B. J., Shorter, J., Strathearn, K. E., Hamamichi, S., Su, L. J., et al. (2008). The Parkinson's disease protein $\alpha$-synuclein disrupts cellular Rab homeostasis. Proc. Natl. Acad. Sci. U.S.A. 105, 145-150. doi: 10.1073/pnas. 0710685105

Gitler, A. D., Chesi, A., Geddie, M. L., Strathearn, K. E., Hamamichi, S., Hill, K. J., et al. (2009). $\alpha$-synuclein is part of a diverse and highly conserved interaction network that includes PARK9 and manganese toxicity. Nat. Genet. 41, 308-315. doi: 10.1038/ng.300

Gong, B., Cao, Z., Zheng, P., Vitolo, O. V., Liu, S., Staniszewski, A., et al. (2006). Ubiquitin hydrolase $U$ ch-L1 rescues $\beta$-amyloid-induced decreases in synaptic function and contextual memory. Cell 126, 775-788. doi: 10.1016/j.cell.2006.06.046

Grinnell, F. (1984). Manganese-dependent cell-substratum adhesion. J. Cell Sci. 65, 61-72.

Gunter, R. E., Puskin, J. S., and Russell, P. R. (1975). Quantitative magnetic resonance studies of manganese uptake by mitochondria. Biophys. J. 15, 319-333. doi: 10.1016/S0006-3495(75)85822-X

Gunter, T. E., and Puskin, J. S. (1972). Manganous ion as a spin label in studies of mitochondrial uptake of manganese. Biophys. J. 12, 625-635. doi: 10.1016/S00063495(72)86108-3

Han, B.-S., Iacovitti, L., Katano, T., Hattori, N., Seol, W., and Kim, K.-S. (2008). Expression of the LRRK2 gene in the midbrain dopaminergic neurons of the substantia nigra. Neurosci. Lett. 442, 190-194. doi: 10.1016/j.neulet.2008. 06.086

He, L., Girijashanker, K., Dalton, T. P., Reed, J., Li, H., Soleimani, M., et al. (2006). ZIP8, member of the solute-carrier-39 (SLC39) metal-transporter family: characterization of transporter properties. Mol. Pharmacol. 70, 171-180. doi: 10.1124/mol.106.024521

He, Q., Du, T., Yu, X., Xie, A., Song, N., Kang, Q., et al. (2011). DMT1 polymorphism and risk of Parkinson's disease. Neurosci. Lett. 501, 128-131. doi: 10.1016/j.neulet.2011.07.001

Hermanson, E., Joseph, B., Castro, D., Lindqvist, E., Aarnisalo, P., Wallén, A., et al. (2003). Nurrl regulates dopamine synthesis and storage in MN9D dopamine cells. Exp. Cell Res. 288, 324-334. doi: 10.1016/S0014-4827(03) 00216-7

Himeno, S., Yanagiya, T., and Fujishiro, H. (2009). The role of zinc transporters in cadmium and manganese transport in mammalian cells. Biochimie 91, 12181222. doi: 10.1016/j.biochi.2009.04.002

Hod, Y., Pentyala, S. N., Whyard, T. C., and El-Maghrabi, M. R. (1999). Identification and characterization of a novel protein that regulates RNA-protein interaction. J. Cell. Biochem. 72, 435-444. doi: 10.1002/(SICI)1097-4644(19990301)72:3 $<435:: A I D-J C B 12>3.0 . C O ; 2-H$

Hsu, L. J., Sagara, Y., Arroyo, A., Rockenstein, E., Sisk, A., Mallory, M., et al. (2000). $\alpha$-synuclein promotes mitochondrial deficit and oxidative stress. Am. J. Pathol. 157, 401-410. doi: 10.1016/S0002-9440(10)64553-1

Huang, C. C., Chu, N. S., Lu, C. S., Chen, R. S., and Calne, D. B. (1998). Longterm progression in chronic manganism: ten years of follow-up. Neurology 50, 698-700. doi: 10.1212/WNL.50.3.698

Huang, C. C., Chu, N. S., Lu, C. S., Chen, R. S., Schulzer, M., and Calne, D. B. (2007). The natural history of neurological manganism over 18 years. Parkinsonism Relat. Disord. 13, 143-145. doi: 10.1016/j.parkreldis.2006.09.002

Huang, C. C., Chu, N. S., Lu, C. S., Wang, J. D., Tsai, J. L., Tzeng, J. L., et al. (1989). Chronic manganese intoxication. Arch. Neurol. 46, 1104-1106. doi: 10.1001/archneur.1989.00520460090018

Huang, C. C., Lu, C. S., Chu, N. S., Hochberg, F., Lilienfeld, D., Olanow, W., et al. (1993). Progression after chronic manganese exposure. Neurology 43, 1479-1483. doi: 10.1212/WNL.43.8.1479

Huang, E., Ong, W. Y., and Connor, J. R. (2004). Distribution of divalent metal transporter-1 in the monkey basal ganglia. Neuroscience 128, 487-496. doi: 10.1016/j.neuroscience.2004.06.055

Ikeda, S., Yamaguchi, Y., Sera, Y., Ohshiro, H., Uchino, S., Yamashita, Y., et al. (2000). Manganese deposition in the globus pallidus in patients with biliary atresia. Transplantation 69, 2339-2343. doi: 10.1097/00007890-20000615000021

Ingersoll, R. T., Montgomery, E. B., and Aposhian, H. V. (1999). Central nervous system toxicity of manganese. II. Cocaine or reserpine inhibit manganese concentration in the rat brain. Neurotoxicology 20, 467-476.

Inoue, E., Hori, S., Narumi, Y., Fujita, M., Kuriyama, K., Kadota, T., et al. (1991). Portal-systemic encephalopathy: presence of basal ganglia lesions with high signal intensity on MR images. Radiology 179, 551-555. doi: 10.1148/radiology.179.2.2014310

Jankovic, J., Chen, S., and Le, W. D. (2005). The role of Nurrl in the development of dopaminergic neurons and Parkinson's disease. Prog. Neurobiol. 77, 128-138. doi: 10.1016/j.pneurobio.2005.09.001

Jellinger, K. A. (2012). Neuropathology of sporadic Parkinson's disease: evaluation and changes of concepts. Mov. Disord. 27, 8-30. doi: 10.1002/mds.23795

Jorge da Silva, C., José Da Rocha, A., Mendes, M., Braga, A., and Jeronymo, S. (2008). Brain manganese deposition depicted by magnetic resonance imaging in a welder. Arch. Neurol. 65, 983-983. doi: 10.1001/archneur.65.7.983

Keen, C. L., Bell, J. G., and Lonnerdal, B. (1986). The effect of age on manganese uptake and retention from milk and infant formulas in rats. J. Nutr. 116, 395-402.

Koller, W. C., Lyons, K. E., and Truly, W. (2004). Effect of levodopa treatment for parkinsonism in welders: a double-blind study. Neurology 62, 730-733. doi: 10.1212/01.WNL.0000113726.34734.15

Kulisevsky, J., Pujol, J., Balanzo, J., Junque, C., Deus, J., Capdevilla, A., et al. (1992). Pallidal hyperintensity on magnetic resonance imaging in cirrhotic patients: clinical correlations. Hepatology 16, 1382-1388. doi: 10.1002/hep.1840 160613

Kuwahara, T., Koyama, A., Gengyo-Ando, K., Masuda, M., Kowa, H., Tsunoda, M., et al. (2006). Familial Parkinson mutant $\alpha$-synuclein causes dopamine neuron dysfunction in transgenic Caenorhabditis elegans. J. Biol. Chem. 281, 334-340. doi: 10.1074/jbc.M504860200

Lansbury, P. T. Jr. (2006). Improving synaptic function in a mouse model of AD. Cell 126, 655-657. doi: 10.1016/j.cell.2006.08.011

Liu, Y., Fallon, L., Lashuel, H. A., Liu, Z., and Lansbury, P. T. Jr. (2002). The UCH-L1 gene encodes two opposing enzymatic activities that affect $\alpha$ synuclein degradation and Parkinson's disease susceptibility. Cell 111, 209-218. doi: 10.1016/S0092-8674(02)01012-7

Lockman, P. R., Roder, K. E., and Allen, D. D. (2001). Inhibition of the rat bloodbrain barrier choline transporter by manganese chloride. J. Neurochem. 79, 588594. doi: 10.1046/j.1471-4159.2001.00589.x 
Lucaciu, C. M., Dragu, C., Copaescu, L., and Morariu, V.V. (1997). Manganese transport through human erythrocyte membranes. An EPR study. Biochim. Biophys. Acta 1328, 90-98. doi: 10.1016/S0005-2736(97)00039-4

Lucchini, R., Albini, E., Placidi, D., Gasparotti, R., Pigozzi, M. G., Montani, G., et al. (2000). Brain magnetic resonance imaging and manganese exposure. Neurotoxicology 21, 769-775.

Lucchini, R. G., Albini, E., Benedetti, L., Borghesi, S., Coccaglio, R., Malara, E. C. et al. (2007). High prevalence of Parkinsonian disorders associated to manganese exposure in the vicinities of ferroalloy industries. Am. J. Ind. Med. 50, 788-800. doi: 10.1002/ajim.20494

Madejczyk, M. S., and Ballatori, N. (2012). The iron transporter ferroportin can also function as a manganese exporter. Biochim. Biophys. Acta 1818, 651-657. doi: 10.1016/j.bbamem.2011.12.002

Malecki, E. A., Radzanowski, G. M., Radzanowski, T. J., Gallaher, D. D., and Greger, J. L. (1996). Biliary manganese excretion in conscious rats is affected by acute and chronic manganese intake but not by dietary fat. J. Nutr. 126, 489-498.

Masliah, E., Rockenstein, E., Veinbergs, I., Mallory, M., Hashimoto, M., Takeda, A., et al. (2000). Dopaminergic loss and inclusion body formation in $\alpha$-synuclein mice: implications for neurodegenerative disorders. Science 287, 1265-1269. doi: 10.1126/science.287.5456.1265

Mason, R. P. (1993). Membrane interaction of calcium channel antagonists modulated by cholesterol. Implications for drug activity. Biochem. Pharmacol. 45, 2173-2183. doi: 10.1016/0006-2952(93)90186-Z

McCord, J. M. (1976). Iron- and manganese-containing superoxide dismutases: structure, distribution, and evolutionary relationships. Adv. Exp. Med. Biol. 74 540-550. doi: 10.1007/978-1-4684-3270-1_45

Mena, I., Marin, O., Fuenzalida, S., and Cotzias, G. C. (1967). Chronic manganese poisoning. Clinical picture and manganese turnover. Neurology 17, 128-136. doi: 10.1212/WNL.17.2.128

Meray, R. K., and Lansbury, P. T. (2007). Reversible monoubiquitination regulates the Parkinson disease-associated ubiquitin hydrolase UCH-L1. J. Biol. Chem. 282, 10567-10575. doi: 10.1074/jbc.M611153200

Mitsumoto, A., and Nakagawa, Y. (2001). DJ-1 is an indicator for endogenous reactive oxygen species elicited by endotoxin. Free Radic. Res. 35, 885-893. doi: 10.1080/10715760100301381

Mitsumoto, A., Nakagawa, Y., Takeuchi, A., Okawa, K., Iwamatsu, A., and Takanezawa, Y. (2001). Oxidized forms of peroxiredoxins and DJ-1 on twodimensional gels increased in response to sublethal levels of paraquat. Free Radic. Res. 35, 301-310. doi: 10.1080/10715760100300831

Morris, C. M., Keith, A. B., Edwardson, J. A., and Pullen, R. G. (1992). Uptake and distribution of iron and transferrin in the adult rat brain. J. Neurochem. 59, 300-306. doi: 10.1111/j.1471-4159.1992.tb08904.x

Murin, R., Verleysdonk, S., Raeymaekers, L., Kaplan, P., and Lehotsky, J. (2006). Distribution of secretory pathway $\mathrm{Ca}^{2+}$ ATPase (SPCA1) in neuronal and glial cell cultures. Cell. Mol. Neurobiol. 26, 1355-1365. doi: 10.1007/s10571-0069042-z

Narhi, L., Wood, S. J., Steavenson, S., Jiang, Y., Wu, G. M., Anafi, D., et al. (1999). Both familial Parkinson's disease mutations accelerate $\alpha$-synuclein aggregation. $J$. Biol. Chem. 274, 9843-9846. doi: 10.1074/jbc.274.14.9843

Newland, M. C., Ceckler, T. L., Kordower, J. H., and Weiss, B. (1989). Visualizing manganese in the primate basal ganglia with magnetic resonance imaging. Exp. Neurol. 106, 251-258. doi: 10.1016/0014-4886(89)90157-X

Parkinson, J. (2002). An essay on the shaking palsy. 1817. J. Neuropsychiatry Clin. Neurosci. 14, 223-236; discussion 222. doi: 10.1176/appi.neuropsych.14.2.223

Petrucelli, L., O’arrell, C., Lockhart, P. J., Baptista, M., Kehoe, K., Vink, L., et al. (2002). Parkin protects against the toxicity associated with mutant $\alpha$-synuclein: proteasome dysfunction selectively affects catecholaminergic neurons. Neuron 36 , 1007-1019. doi: 10.1016/S0896-6273(02)01125-X

Pujol, A., Pujol, J., Graus, F., Rimola, A., Peri, J., Mercader, J. M., et al. (1993). Hyperintense globus pallidus on T1-weighted MRI in cirrhotic patients is associated with severity of liver failure. Neurology 43, 65-69. doi: 10.1212/WNL. 43.1_Part_1.65

Quadri, M., Federico, A., Zhao, T., Breedveld, G. J., Battisti, C., Delnooz, C., et al. (2012). Mutations in SLC30A10 cause parkinsonism and dystonia with hypermanganesemia, polycythemia, and chronic liver disease. Am. J. Hum. Genet. 90, 467-477. doi: 10.1016/j.ajhg.2012.01.017

Racette, B. A. (2013). Manganism in the 21st century: the Hanninen lecture. Neurotoxicology doi: 10.1016/j.neuro.2013.09.007 [Epub ahead of print].
Racette, B. A., Criswell, S. R., Lundin, J. I., Hobson, A., Seixas, N., Kotzbauer, P. T., et al. (2012). Increased risk of parkinsonism associated with welding exposure. Neurotoxicology 33, 1356-1361. doi: 10.1016/j.neuro.2012.08.011

Racette, B. A., Mcgee-Minnich, L., Moerlein, S. M., Mink, J. W., Videen, T. O., and Perlmutter, J. S. (2001). Welding-related parkinsonism: clinical features, treatment, and pathophysiology. Neurology 56, 8-13. doi: 10.1212/WNL.56.1.8

Rodier, J. (1955). Manganese poisoning in Moroccan miners. Br. J. Ind. Med. 12, 21-35. doi: 10.1136/oem.12.1.21

Roholt, O. A. Jr., and Greenberg, D. M. (1956). Liver arginase. IV. Effect of pH on kinetics of manganese-activated enzyme. Arch. Biochem. Biophys. 62, 454-470. doi: 10.1016/0003-9861(56)90144-8

Rose, C., Butterworth, R. F., Zayed, J., Normandin, L., Todd, K., Michalak, A., et al. (1999). Manganese deposition in basal ganglia structures results from both portal-systemic shunting and liver dysfunction. Gastroenterology 117, 640-644. doi: 10.1016/S0016-5085(99)70457-9

Roth, J. A. (2009). Are there common biochemical and molecular mechanisms controlling manganism and parkisonism. Neuromolecular Med. 11, 281-296. doi: 10.1007/s12017-009-8088-8

Sacchetti, P., Mitchell, T. R., Granneman, J. G., and Bannon, M. J. (2001). Nurr1 enhances transcription of the human dopamine transporter gene through a novel mechanism. J. Neurochem. 76, 1565-1572. doi: 10.1046/j.1471-4159.2001. 00181.x

Sakurada, K., Ohshima-Sakurada, M., Palmer, T. D., and Gage, F. H. (1999). Nurr1, an orphan nuclear receptor, is a transcriptional activator of endogenous tyrosine hydroxylase in neural progenitor cells derived from the adult brain. Development 126, 4017-4026.

Salazar, J., Mena, N., Hunot, S., Prigent, A., Alvarez-Fischer, D., Arredondo, M., et al. (2008). Divalent metal transporter 1 (DMT1) contributes to neurodegeneration in animal models of Parkinson's disease. Proc. Natl. Acad. Sci. U.S.A. 105, 1857818583. doi: 10.1073/pnas.0804373105

Sandstead, H. H. (1986). A brief history of the influence of trace elements on brain function. Am. J. Clin. Nutr. 43, 293-298.

Seve, M., Chimienti, F., Devergnas, S., and Favier, A. (2004). In silico identification and expression of SLC30 family genes: an expressed sequence tag data mining strategy for the characterization of zinc transporters' tissue expression. BMC Genomics 5:32. doi: 10.1186/1471-2164-5-32

Shendelman, S., Jonason, A., Martinat, C., Leete, T., and Abeliovich, A. (2004). DJ-1 is a redox-dependent molecular chaperone that inhibits $\alpha$-synuclein aggregate formation. PLoS Biol. 2:e362. doi: 10.1371/journal.pbio.0020362

Shimura, H., Hattori, N., Kubo, S.-I., Mizuno, Y., Asakawa, S., Minoshima, S., et al. (2000). Familial Parkinson disease gene product, parkin, is a ubiquitin-protein ligase. Nat. Genet. 25, 302-305. doi: 10.1038/77060

Shinotoh, H., Snow, B. J., Chu, N. S., Huang, C. C., Lu, C. S., Lee, C., et al. (1997). Presynaptic and postsynaptic striatal dopaminergic function in patients with manganese intoxication: a positron emission tomography study. Neurology 48, 1053-1056. doi: 10.1212/WNL.48.4.1053

Sikk, K., Haldre, S., Aquilonius, S. M., Asser, A., Paris, M., Roose, Ä., et al. (2013). Manganese-induced parkinsonism in methcathinone abusers: bio-markers of exposure and follow-up. Eur. J. Neurol. 20, 915-920. doi: 10.1111/ene.12088

Smialowicz, R. J., Luebke, R. W., Rogers, R. R., Riddle, M. M., and Rowe, D. G. (1985). Manganese chloride enhances natural cell-mediated immune effector cell function: effects on macrophages. Immunopharmacology 9, 1-11. doi: 10.1016/0162-3109(85)90040-2

Smith, E. A., Newland, P., Bestwick, K. G., and Ahmed, N. (2012). Increased whole blood manganese concentrations observed in children with iron deficiency anaemia. J. Trace Elem. Med. Biol. 27, 65-69. doi: 10.1016/j.jtemb.2012.07.002

Smith, W. W., Pei, Z., Jiang, H., Moore, D. J., Liang, Y., West, A. B., et al. (2005). Leucine-rich repeat kinase 2 (LRRK2) interacts with parkin, and mutant LRRK2 induces neuronal degeneration. Proc. Natl. Acad. Sci. U.S.A. 102, 18676-18681. doi: 10.1073/pnas.0508052102

Sossi, V., De La Fuente-Fernández, R., Schulzer, M., Troiano, A. R., Ruth, T. J., and Stoessl, A. J. (2007). Dopamine transporter relation to dopamine turnover in Parkinson's disease: a positron emission tomography study. Ann. Neurol. 62, 468-474. doi: 10.1002/ana.21204

Stamelou, M., Tuschl, K., Chong, W. K., Burroughs, A. K., Mills, P. B., Bhatia, K. P., et al. (2012). Dystonia with brain manganese accumulation resulting from SLC30A10 mutations: a new treatable disorder. Mov. Disord. 27, 1317-1322. doi: $10.1002 / \mathrm{mds} .25138$ 
Suzuki, N., Nakamura, Y., Kobayashi, N., and Sato, T. (1975). On metal elements in pure pigment gallstones. Tohoku J. Exp. Med. 116, 233-240. doi: 10.1620/tjem.116.233

Takahashi, K., Taira, T., Niki, T., Seino, C., Iguchi-Ariga, S. M. M., and Ariga, H. (2001). DJ-1 positively regulates the androgen receptor by impairing the binding of PIASx $\alpha$ to the receptor. J. Biol. Chem. 276, 37556-37563. doi: 10.1074/jbc.M101730200

Tan, J., Zhang, T., Jiang, L., Chi, J., Hu, D., Pan, Q., et al. (2011). Regulation of intracellular manganese homeostasis by Kufor-Rakeb syndrome-associated ATP13A2 protein. J. Biol. Chem. 286, 29654-29662. doi: 10.1074/jbc.M111.233874

Tuschl, K., Clayton, P. T., Gospe, S. M. Jr., Gulab, S., Ibrahim, S., Singhi, P., et al. (2012). Syndrome of hepatic cirrhosis, dystonia, polycythemia, and hypermanganesemia caused by mutations in SLC30A10, a manganese transporter in man. Am. J. Hum. Genet. 90, 457-466. doi: 10.1016/j.ajhg.2012.01.018

Urrutia, P., Aguirre, P., Esparza, A., Tapia, V., Mena, N. P., Arredondo, M., et al. (2013). Inflammation alters the expression of DMT1, FPN1 and hepcidin, and it causes iron accumulation in central nervous system cells. J. Neurochem. 126, 541-549. doi: 10.1111/jnc.12244

Valente, E. M., Abou-Sleiman, P. M., Caputo, V., Muqit, M. M. K., Harvey, K., Gispert, S., et al. (2004). Hereditary early-onset Parkinson's disease caused by mutations in PINK1. Science 304, 1158-1160. doi: 10.1126/science.1096284

Wedler, F. C., and Denman, R. B. (1984). Glutamine synthetase: the major Mn(II) enzyme in mammalian brain. Curr. Top. Cell. Regul. 24, 153-169. doi: 10.1016/B978-0-12-152824-9.50021-6

Weissenborn, K., Ehrenheim, C., Hori, A., Kubicka, S., and Manns, M. P. (1995). Pallidal lesions in patients with liver cirrhosis: clinical and MRI evaluation. Metab. Brain Dis. 10, 219-231. doi: 10.1007/BF02081027

Wilkinson, K. D. (2000). Ubiquitination and deubiquitination: targeting of proteins for degradation by the proteasome. Semin. Cell Dev. Biol. 11, 141-148. doi: $10.1006 / \mathrm{scdb} .2000 .0164$

Williams, K., Wilson, M. A., and Bressler, J. (2000). Regulation and developmental expression of the divalent metal-ion transporter in the rat brain. Cell. Mol. Biol. (Noisy-le-grand) 46, 563-571.

Yang, Y., Gehrke, S., Imai, Y., Huang, Z., Ouyang, Y., Wang, J.-W., et al. (2006). Mitochondrial pathology and muscle and dopaminergic neuron degeneration caused by inactivation of Drosophila Pink1 is rescued by Parkin. Proc. Natl. Acad. Sci. U.S.A. 103, 10793-10798. doi: 10.1073/pnas.0602493103

Yang, Y., Nishimura, I., Imai, Y., Takahashi, R., and Lu, B. (2003). Parkin suppresses dopaminergic neuron-selective neurotoxicity induced by Pael-R in drosophila. Neuron 37, 911-924. doi: 10.1016/S0896-6273(03) 00143-0

Yin, Z., Jiang, H., Lee, E. S., Ni, M., Erikson, K. M., Milatovic, D., et al. (2010). Ferroportin is a manganese-responsive protein that decreases manganese cytotoxicity and accumulation. J. Neurochem. 112, 1190-1198. doi: 10.1111/j.1471-4159. 2009.06534.x

Zhou, C., Huang, Y., Shao, Y., May, J., Prou, D., Perier, C., et al. (2008). The kinase domain of mitochondrial PINK1 faces the cytoplasm. Proc. Natl. Acad. Sci. U.S.A. 105, 12022-12027. doi: 10.1073/pnas.0802814105

Zhou, Z. D., Kerk, S. Y., Xiong, G. G., and Lim, T. M. (2009). Dopamine autooxidation aggravates non-apoptotic cell death induced by over-expression of human A53T mutant alpha-synuclein in dopaminergic PC12 cells. J. Neurochem. 108, 601-610. doi: 10.1111/j.1471-4159.2008.05795.x

Zlotkin, S. H., Atkinson, S., and Lockitch, G. (1995). Trace elements in nutrition for premature infants. Clin. Perinatol. 22, 223-240.

Conflict of Interest Statement: The authors declare that the research was conducted in the absence of any commercial or financial relationships that could be construed as a potential conflict of interest.

Received: 21 April 2014; accepted: 18 July 2014; published online: 04 August 2014. Citation: Chen P, Parmalee N and Aschner M (2014) Genetic Factors and ManganeseInduced Neurotoxicity. Front. Genet. 5:265. doi: 10.3389/fgene.2014.00265

This article was submitted to Toxicogenomics, a section of the journal Frontiers in Genetics.

Copyright (C) 2014 Chen, Parmalee and Aschner. This is an open-access article distributed under the terms of the Creative Commons Attribution License (CC BY). The use, distribution or reproduction in other forums is permitted, provided the original author(s) or licensor are credited and that the original publication in this journal is cited, in accordance with accepted academic practice. No use, distribution or reproduction is permitted which does not comply with these terms. 